\title{
Correction to: The selective orexin-2 antagonist seltorexant (JNJ-42847922/MIN-202) shows antidepressant and sleep-promoting effects in patients with major depressive disorder
}

Kasper Recourt ${ }^{1,2}$, Peter de Boer ${ }^{3}$, Rob Zuiker $\mathbb{D}^{1}$, Remy Luthringer ${ }^{4}$, Justine Kent ${ }^{5}$, Peter van der Ark ${ }^{3}$, Ilse Van Hove ${ }^{3}$, Joop van Gerven ${ }^{1,2}$, Gabriel Jacobs ${ }^{1,2}$, Luc van Nueten ${ }^{3}$ and Wayne Drevets ${ }^{3}$

\section{Correction to: Translational Psychiatry}

https://doi.org/10.1038/s41398-019-0553-2

published online 3 September 2019

In the original Article, Tables two and three had formatting issues which affected their clarity. This has been corrected in the PDF and HTML versions of this Article.

Correspondence: Kasper Recourt (Krecourt@chdr.nl)

${ }^{1}$ Centre for Human Drug Research, Leiden, The Netherlands

${ }^{2}$ Leiden University Medical Center, Leiden, The Netherlands

3Janssen Research and Development, Division of Janssen Pharmaceutica N.V., Beerse, Belgium

${ }^{4}$ Minerva Neurosciences, Waltham, MA, USA

${ }^{5}$ Sunovion, Fort Lee, NJ, USA

These authors contributed equally: Kasper Recourt, Peter de Boer

(c) The Author(s) 2019

(c) (i) Open Access This article is licensed under a Creative Commons Attribution 4.0 International License, which permits use, sharing, adaptation, distribution and reproduction cc) in any medium or format, as long as you give appropriate credit to the original author(s) and the source, provide a link to the Creative Commons license, and indicate if changes were made. The images or other third party material in this article are included in the article's Creative Commons license, unless indicated otherwise in a credit line to the material. If material is not included in the article's Creative Commons license and your intended use is not permitted by statutory regulation or exceeds the permitted use, you will need to obtain permission directly from the copyright holder. To view a copy of this license, visit http://creativecommons.org/licenses/by/4.0/. 